\title{
CORRECTION
}

\section{Correction to: Long-term treatment of endometriosis with dienogest: retrospective analysis of efficacy and safety in clinical practice}

\author{
Thomas Römer ${ }^{1}$ (1)
}

Published online: 22 November 2018

c) Springer-Verlag GmbH Germany, part of Springer Nature 2018

\section{Correction to: \\ Archives of Gynecology and Obstetrics \\ (2018) 298:747-753 \\ https://doi.org/10.1007/s00404-018-4864-8}

In the original publication of the article, the word 'laparotomy' has been presented in the proofs instead of 'laparoscopy' in the below places:

In the first paragraph, 6th line in Introduction section. In the fifth paragraph, 8th line in Introduction section. In the first paragraph, 7th line in Materials and methods section.

In the second paragraph, 4th line in Discussion section.

The original article can be found online at https://doi.org/10.1007/ s00404-018-4864-8.

Thomas Römer

roemerth62@gmail.com; Thomas.Roemer@evk-koeln.de

1 Obstetrics and Gynecology Department, Academic Hospital Weyertal, University of Cologne, 50931 Cologne, Germany 